\title{
Balkanologie
}

Balkanologie Revue d'études pluridisciplinaires

Vol. VIII, $n^{\circ} 2$ | 2004

Volume VIII Numéro 2

\section{Bruneau (Michel), Papoulidis (Kyriakos), La mémoire de l'hellénisme réfugié : les monuments commémoratifs en Grèce (1936-2004)}

Thessaloniki : Adelfi Kyriakidi, 2004,132 p.

Bernard Lory

\section{CpenEdition}

Journals

Édition électronique

URL : http://journals.openedition.org/balkanologie/2047

DOI : $10.4000 /$ balkanologie.2047

ISSN : 1965-0582

Éditeur

Association française d'études sur les Balkans (Afebalk)

Édition imprimée

Date de publication : 1 décembre 2004

ISSN : 1279-7952

\section{Référence électronique}

Bernard Lory, «Bruneau (Michel), Papoulidis (Kyriakos), La mémoire de l'hellénisme réfugié : les monuments commémoratifs en Grèce (1936-2004) ", Balkanologie [En ligne], Vol. VIII, n² 2 | 2004, mis en ligne le 20 janvier 2010, consulté le 17 décembre 2020. URL : http://journals.openedition.org/ balkanologie/2047 ; DOI : https://doi.org/10.4000/balkanologie.2047

Ce document a été généré automatiquement le 17 décembre 2020.

(c) Tous droits réservés 


\title{
Bruneau (Michel), Papoulidis (Kyriakos), La mémoire de l'hellénisme réfugié : les monuments commémoratifs en Grèce (1936-2004)
}

Thessaloniki : Adelfi Kyriakidi, 2004,132 p.

\author{
Bernard Lory
}

\section{RÉFÉRENCE}

Bruneau (Michel), Papoulidis (Kyriakos), La mémoire de l'hellénisme réfugié : les monuments commémoratifs en Grèce (1936-2004), Thessaloniki : Adelfi Kyriakidi, 2004,132 p.

1 Depuis l'œuvre magistrale dirigée par Pierre Nora, l'étude des lieux de mémoire a atteint le monde balkanique où la déconstruction des discours et des représentations historiques va bon train ces dernières années. Ce petit ouvrage s'inscrit directement dans cette mouvance. C'est le fruit d'une collaboration entre un géographe français et un historien grec, combinaison heureuse qui permet d'éviter tout dérapage idéologique ou disciplinaire : la géographie ramène toujours à la matérialité du monument (site, matériaux, etc.), tandis que l'histoire le situe dans son contexte chronologique; la combinaison des deux permet d'éclairer le message véhiculé dans le bronze ou le marbre. L'ouvrage se compose du texte en grec (PP.9-59). puis en français (pp.63-103) et d'un cahier iconographique (pp. 109-130).

2 L'étude porte sur une soixantaine de monuments situés en Grèce continentale et consacrés aux «patries inoubliables» dont étaient issus presque 1,5 millions de réfugiés des années 1916-1924, c'est à dire l'Ionie, le Pont, la Cappadoce et la Thrace (la Roumélie orientale et Constantinople sont évoquées incidemment p. 86). L'étude de ces 
monuments, dans son aspect un peu formaliste (cadre légal, localisation, financement, typologie, analyse des représentations, pratiques commémoratives) contribue à éclairer une question historique majeure: comment une population importante de réfugiés parvient-elle à s'intégrer? Comment marquer son identité spécifique sans rompre le discours d'unité nationale? Comment allier le sentiment de victime du passé à l'affirmation de sa foi dans l'avenir?

Il ressort de l'étude de M. Bruneau et K. Papoulidis que l'inscription monumentale des réfugiés commence tardivement, avec la fondation du Foyer de la Nouvelle Smyrne (1939-1955) due à la générosité de la diaspora micrasiate, laquelle comprend quelques très grosses fortunes. Très tôt, la communauté pontique s'autonomise parmi les réfugiés et fonde son propre centre, également situé à Nea Smyrni. Quelques monuments sont édifiés durant les années 60 , mais la véritable vague commémorative ne commence guère qu'avec les années 90 , soit 70 ans après la Megali Katastrofi, à un moment où les derniers acteurs vivants du drame disparaissent. Les auteurs constatent le fait, mais ne proposent pas grand chose en fait d'explication : le désir de garder de bonnes relations avec la Turquie (pp. 65-66) n'est certainement pas la caractéristique majeure de la politique grecque au long du $\mathrm{XX}^{\mathrm{e}}$ siècle. La réponse doit certainement être cherchée du côté de la relecture du passé national sous le PASOK.

4 L'étude fait clairement ressortir l'affirmation de spécificité des réfugiés originaires du Pont et de leurs descendants, dont l'expression monumentale n'est pas proportionnée au poids démographique. Ce groupe développe également un vocabulaire iconographique particulièrement riche (thèmes de l'akrite, de l'antartis, monastères de référence, costume, danse, musique). En comparaison, les représentations de la patrie inoubliable d'Ionie apparaissent mièvres et conventionnelles. Là encore le lecteur reste un peu sur sa faim: pourquoi certains descendants de réfugiés mettent-ils plus en avant leur passé que d'autres? Quels sont les enjeux de la reconnaissance par le parlement grec du génocide des Pontiques en 1994? Pourquoi ce mouvement d'affirmation communautaire se poursuit-il si activement de nos jours? Sur la base de l'analyse rigoureuse du corpus monumental, qui fournit un bon angle d'approche de ces questions, des thèmes de réflexion s'ouvrent à la recherche. Une comparaison avec les pays balkaniques voisins ferait ressortir la similitude des moyens artistiques mis en œuvre. 